(2) Open Access Full Text Article

\title{
Association of Chronotypes and Sleep Disturbance with Perceived Job Stressors and Stress Response: A Covariance Structure Analysis
}

This article was published in the following Dove Press journal:

Neuropsychiatric Disease and Treatment

\author{
Hitoshi Miyama $\mathbb{D}^{1,2}$ \\ Akiyoshi Shimura (D) \\ Wataru Furuichi' \\ Tomoteru Seki ${ }^{1}$ \\ Kotaro Ono' \\ Jiro Masuya $\mathbb{D}^{1}$ \\ Yuko Odagiri $\mathbb{1}^{3}$ \\ Shigeru Inoue $\mathbb{D}^{3}$ \\ Takeshi Inoue (D) \\ 'Department of Psychiatry, Tokyo \\ Medical University, Tokyo 160-0023, \\ Japan; ${ }^{2}$ Department of Psychiatry, \\ Maruyamasou Hospital, Ishioka, Ibaraki \\ 3I5-0I I6, Japan; ${ }^{3}$ Department of \\ Preventive Medicine and Public Health, \\ Tokyo Medical University, Tokyo I60- \\ 8402, Japan
}

Background: Chronotype, which is a person's circadian characteristics throughout a day, greatly influences a person's lifestyle, health, and sleep pattern; however, the association between job stress and chronotype remains unknown to date. Therefore, in this study, we analyzed the effects of chronotype on the job stress response, and the mediating effects of sleep disturbance using path analysis.

Methods: A cross-sectional survey was conducted on 535 adult volunteers (239 men and 296 women; average age, $41.2 \pm 11.9$ years) from the community. Participants were evaluated using the Diurnal Type Scale for chronotype, Pittsburg Sleep Quality Index for sleep disturbance, Brief Job Stress Questionnaire for job stressors, and the psychological and physical stress response (PPSR). To investigate the association between chronotype, sleep disturbance, perceived job stressors, and PPSR, a covariance structure analysis was performed.

Results: The eveningness chronotype had a significant weak direct effect on sleep disturbance, perceived job stressors, and PPSR, and had a significant indirect effect through sleep disturbance. The perceived job stressors indirectly increased PPSR through sleep disturbance. Sleep disturbance mediated the effects of the eveningness chronotype and perceived job stressors on PPSR. This model accounted for $37.3 \%$ of the variability in PPSR of adult workers.

Conclusion: Chronotype affected PPSR through sleep disturbance. Therefore, improving the sleep disturbance of workers with the eveningness chronotype may reduce their stress response.

Keywords: eveningness chronotype, sleep disturbance, job stress, Diurnal Type Scale

\section{Introduction}

Chronotype is the characteristics of a person's circadian rhythm and time preference of activity throughout the day. ${ }^{1}$ People with an early-type activity preference are called the morning type, and people with a late-type activity preference are called the evening type. The phenotype is different for each individual and is known to be determined by genetic and environmental factors and to be strongly influenced by age, ie, older people tend to have the morning chronotype. ${ }^{2-4}$ Self-administered questionnaires, such as the Diurnal Type Scale (DTS), the MorningnessEveningness Questionnaire, and the Munich Chronotype Questionnaire are used to investigate chronotypes. ${ }^{5-7}$ For evening type people, sleep duration tends to be shortened on weekdays when time is restricted, owing to factors such as work, and
Correspondence: Akiyoshi Shimura Department of Psychiatry, Tokyo Medical University, 6-7-I Nishishinjuku, ShinjukuKu, Tokyo 160-0023, Japan

Tel +8I-3-3342-6III

Fax +8I-3-3340-4499

Email sim@tokyo-med.ac.jp 
daytime sleepiness is increased by sleep debt. ${ }^{8}$ For this reason, evening type people are reported to be more likely to have sleep disturbance and depression than morning type people. ${ }^{9}$ A meta-analysis also pointed out that the eveningness chronotype is associated with mood problems, such as depression and higher suicide rates. ${ }^{10,11}$ In particular, in young people, the eveningness chronotype may affect depression through sleep disturbance. ${ }^{12}$ Therefore, chronotype is considered to have substantial effects on a person's overall mental health in connection with its effects on sleep disturbance. Sleep disturbance is associated with not only chronotype but also various health problems. A meta-analysis has shown that sleep disturbance increases the risk of developing depression and worsens the prognosis of life. ${ }^{13}$

For adult populations, occupational stress also affects psychosomatic conditions. The Brief Job Stress Questionnaire (BJSQ) is a self-administered questionnaire to evaluate job stress and is used as an indicator of workers' stress. ${ }^{14,15}$ In particular, a high score on the psychological and physical stress response (PPSR), which is a subitem of the BJSQ, is reportedly a risk factor for the onset of depression in workers. ${ }^{16}$ Job stress and sleep disturbance are closely associated, and severe job stress leads to insomnia. ${ }^{17,18}$ We recently reported that sleep disturbance mediates the effects of job stressors on PPSR. ${ }^{19}$

As mentioned above, chronotype and job stressors are associated with sleep disturbance, ${ }^{9,17,18}$ and sleep disturbance is associated with PPSR. ${ }^{18}$ However, to our knowledge, the association between chronotype, job stressors, and PPSR has not been reported to date. Furthermore, complex associations as to how chronotype and sleep disturbance affect PPSR have not been analyzed. Therefore, the aim of this study was to investigate how chronotype influences job stress through sleep disturbance. As the eveningness affects overall mental health, ${ }^{9-12}$ we hypothesized that the eveningness affects perceived job stressors, which are subjective evaluations of job stressors, as well as sleep disturbance, and exacerbates PPSR through these effects. We verified this hypothesis by path analysis together with covariance structure analysis. Although chronotype changes with age, ${ }^{20-22}$ it is innate and difficult to change owing to external factors. ${ }^{23-25}$ Accordingly, in this path model, we defined chronotype as an exogenous variable. The indirect effects of the eveningness chronotype on sleep disturbance and PPSR through perceived job stressors were also analyzed by this path analysis.

\section{Subjects and Methods}

\section{Subjects}

From April 2017 to April 2018, self-administered questionnaires were distributed to 1237 nonclinical adult volunteers from the community, who were recruited by convenience sampling through our acquaintances at Tokyo Medical University. Among them, we conducted a study on 535 workers (239 men and 296 women; average age: $41.2 \pm 11.9$ years), who gave their informed consent and returned complete responses to the questionnaires (Table 1). This study was part of a larger study, in which several questionnaires were investigated. ${ }^{26}$ In terms of occupational contracts, there were 454 regular employees, 56 part-time employees, 6 temporary employees, and 15 others (Table 2). Regarding job class, there were 388 general-class employees, 63 section-manager class employees, and 7 employees of manager level or higher. Working conditions were inflexible in 324 workers, discretionary in 24

Table I Characteristics of the Subjects and Their Correlation with PPSR Scores on BJSQ or Effects on PPSR Scores

\begin{tabular}{|c|c|c|}
\hline Characteristics & $\begin{array}{l}\text { Value } \\
\text { (Number } \\
\text { or Mean } \pm \\
\text { SD) }\end{array}$ & $\begin{array}{l}\text { Correlation with PPSR } \\
\text { Score (r) or Effects on } \\
\text { PPSR Score (Mean } \pm \\
\text { SD, t-test) }\end{array}$ \\
\hline Age & $41.2 \pm 11.9$ & $r=-0.094, p=0.030$ \\
\hline Sex (men: women) & 239: 296 & $\begin{array}{l}\text { Men: } 49.9 \pm 14.0 \text { vs } \\
\text { women: } 54.3 \pm 14.3 \text {, } \\
p<0.001 \text { (t-test) }\end{array}$ \\
\hline Education, years & $14.7 \pm 1.8$ & $r=-0.032, p=0.456$ \\
\hline $\begin{array}{l}\text { Marital status } \\
\text { (married: unmarried) }\end{array}$ & 346: 185 & $\begin{array}{l}\text { Married: } 50.4 \pm 13.7 \text { vs } \\
\text { unmarried: } 55.9 \pm 14.9 \text {, } \\
p<0.00 \text { I (t-test) }\end{array}$ \\
\hline Living alone (yes: no) & II2: 423 & $\begin{array}{l}\text { Yes: } 54.4 \pm 14.9 \text { vs no: } 51.8 \\
\pm 14.1, p=0.088 \text { (t-test) }\end{array}$ \\
\hline Number of offspring & $1.3 \pm 1.3$ & $r=-0.064, p=0.143$ \\
\hline $\begin{array}{l}\text { Comorbidity of } \\
\text { physical disease (yes: } \\
\text { no) }\end{array}$ & I01: 434 & $\begin{array}{l}\text { Yes: } 52.1 \pm 13.7 \text { vs no: } 52.4 \\
\pm 14.4, p=0.085 \text { (t-test) }\end{array}$ \\
\hline $\begin{array}{l}\text { First-degree relative } \\
\text { with psychiatric } \\
\text { disease (yes: no) }\end{array}$ & 54: 431 & $\begin{array}{l}\text { Yes: } 53.5 \pm 13.6 \text { vs no: } 52.0 \\
\pm 14.3, p=0.446 \text { (t-test) }\end{array}$ \\
\hline
\end{tabular}

Notes: Data are presented as means \pm SD or numbers. $r=$ Pearson correlation coefficient.

Abbreviations: BJSQ, Brief Job Stress Questionnaire; PPSR, psychological and physical stress response. 
Table 2 Characteristics of Adult Workers and Their Effects on PPSR

\begin{tabular}{|c|c|c|c|}
\hline & $\begin{array}{l}\text { Number of } \\
\text { Subjects }\end{array}$ & $\begin{array}{l}\text { Mean } \\
\text { PPSR } \pm \\
\text { SD }\end{array}$ & ANOVA \\
\hline $\begin{array}{l}\text { Occupational contracts } \\
\text { Regular } \\
\text { Part-time } \\
\text { Temporary } \\
\text { Others }\end{array}$ & $\begin{array}{l}454 \\
56 \\
6 \\
15\end{array}$ & $\begin{array}{l}53.7 \pm 14.7 \\
55.2 \pm 15.3 \\
59.5 \pm 18.1 \\
50.3 \pm 10.7\end{array}$ & $\begin{array}{l}F(3,527) \\
=0.758 \\
p=0.518\end{array}$ \\
\hline $\begin{array}{l}\text { Job class } \\
\text { General class } \\
\text { Section manager class } \\
\text { Manager's level or } \\
\text { higher }\end{array}$ & $\begin{array}{l}388 \\
63 \\
7\end{array}$ & $\begin{array}{l}54.1 \pm 14.4 \\
51.7 \pm 15.7 \\
41.9 \pm 8.6\end{array}$ & $\begin{array}{l}F(2,455) \\
=3.113 \\
p=0.045\end{array}$ \\
\hline $\begin{array}{l}\text { Working condition } \\
\text { Inflexible } \\
\text { Discretionary } \\
\text { Flexible } \\
\text { Shift work (not } \\
\text { including night shift) } \\
\text { Shift work (including } \\
\text { night shift) } \\
\text { Others }\end{array}$ & $\begin{array}{l}324 \\
24 \\
5 \\
26 \\
109 \\
2\end{array}$ & $\begin{array}{l}54.0 \pm 14.7 \\
45.1 \pm 11.4 \\
45.4 \pm 11.8 \\
57.1 \pm 16.0 \\
54.4 \pm 14.0 \\
32.5 \pm 2.1\end{array}$ & $\begin{array}{l}F(5,484) \\
=3.256 \\
p=0.007\end{array}$ \\
\hline $\begin{array}{l}\text { Overtime work hours } \\
\text { (/month) } \\
\leq 20 \text { hours } \\
21-40 \text { hours } \\
41-60 \text { hours } \\
\geq 61 \text { hours }\end{array}$ & $\begin{array}{l}358 \\
74 \\
29 \\
16\end{array}$ & $\begin{array}{l}54.2 \pm 13.9 \\
54.7 \pm 17.6 \\
52.8 \pm 15.6 \\
54.3 \pm 17.6\end{array}$ & $\begin{array}{l}F(3,467) \\
=0.836 \\
p=0.584\end{array}$ \\
\hline
\end{tabular}

Notes: Data are presented as means \pm SD or numbers. Bonferroni test showed no significant difference between groups in job class and working condition.

workers, flexible in 5 workers, shift work (not including night shifts) in 26 workers, shift work (including night shifts) in 109 workers, and others in 2 workers. Overtime work hours were $20 \mathrm{~h}$ or less for 358 workers, 21-40 h for 74 workers, $41-60 \mathrm{~h}$ for 29 workers, and 61 $\mathrm{h}$ or more for 16 workers. The questionnaire for demographic information and the following three questionnaires were anonymously surveyed. Participation in this study was voluntary and the participants were informed that no disadvantage would result from not participating in the study. They were also explained that the information collected would be made anonymous and not leaked to the outside. No special exclusion criteria were set. The study was approved by the ethics committee of Tokyo Medical University in accordance with the Helsinki Declaration. (study approval no.: SH3502)

\section{Survey by Self-Administered}

\section{Questionnaires}

\section{Diurnal Type Scale (DTS)}

The DTS is a self-administered questionnaire to determine the diurnal type (morningness or eveningness disposition on sleep/wake behavior), and the Japanese version of the DTS was used. ${ }^{27}$ Morning-active (morningness) individuals are known to rise earlier and go to bed earlier than evening-active (eveningness) individuals. ${ }^{7,27}$ DTS consists of seven components on a 4-point scale (1-4). The total score (7-28 points) is calculated and evaluated; a higher score indicates the morningness chronotype and a lower score indicates the eveningness chronotype.

\section{Japanese Version of the Pittsburgh Sleep Quality Index (PSQI)}

The Japanese version of PSQI is a self-administered questionnaire consisting of 18 items to evaluate subjective sleep quality during the previous month. ${ }^{28,29}$ PSQI categorizes seven components on a 4-point scale (0-3). The total score ( $0-21$ points) is calculated and evaluated; a higher score indicates that sleep is impaired.

\section{Brief Job Stress Questionnaire (BJSQ)}

BJSQ is a self-administered questionnaire on job stress, consisting of a total of 57 items. ${ }^{14,15}$ BJSQ consists of the following four parts: perceived job stressors, PPSR, social support, and satisfaction. Regarding perceived job stressors, there are a total of 17 items, including quantitative job overload, qualitative job overload, physical demands, job control, skill utilization, interpersonal conflict, poor physical environment, suitable job, and meaningfulness of work. These are subjectively assessed, and for this reason, they are referred to as perceived job stressors. PPSR is composed of 29 items, including vigor, irritability, fatigue, anxiety, depression, and physical complaints. Each item is evaluated on a 4-point scale (1-4). In this study, the total scores for perceived job stressors and PPSR were calculated, and the higher the total score, the higher the stress.

\section{Structural Equation Modeling and Statistical Analysis}

A path model was built (Figure 1), in which chronotype indirectly affected PPSR through perceived job stressors and sleep disturbance, and the model was analyzed by covariance structure analysis with the robust maximum likelihood estimation method. For statistical analysis, 


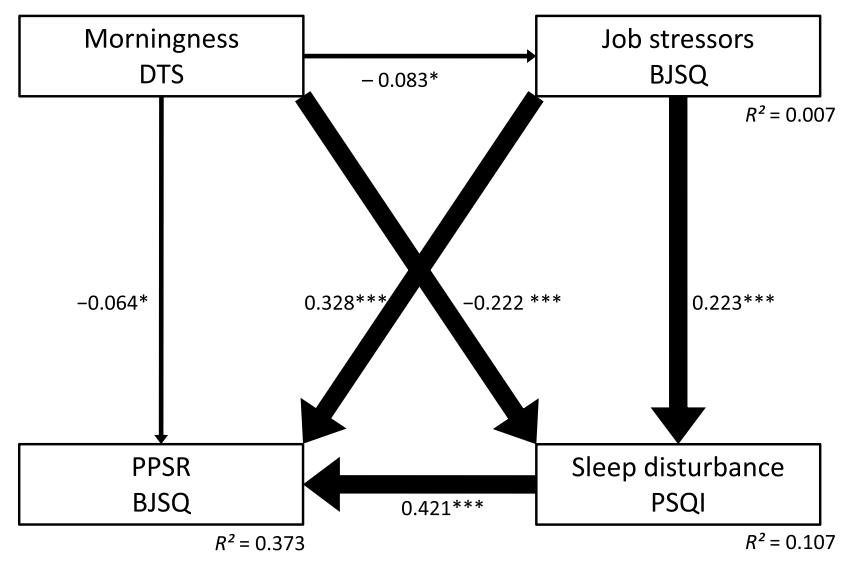

Figure I Results of the path analysis. Path analysis of the data of 535 adult workers regarding Diurnal Type Scale (DTS) score, Pittsburgh Sleep Quality Index (PSQI) global score, perceived job stressors on the Brief Job Stress Questionnaire (BJSQ), and psychological and physical stress response (PPSR) on the BJSQ. The solid arrows represent statistically significant direct paths. The numbers beside the arrows show the standardized path coefficients (minimum: $-I$; maximum: I). ${ }_{p}<<$ $0.05, * * * p<0.001$

SPSS Statistics Version 25 (SPSS, Chicago, IL, USA) and Mplus version 8.0 (Muthén \& Muthén, Los Angeles, CA, USA) were used. As the model used in this study is a saturation model, no goodness-of-fit index was used. All coefficients of the covariance structure analysis were standardized. For comparison between demographic information and questionnaire data, Pearson correlation coefficient analysis, the Student's $t$-test, or ANOVA followed by the Bonferroni test were performed using SPSS
Statistics Version 25 (SPSS). A $p$-value of less than 0.05 was considered to indicate a statistically significant difference.

\section{Results}

\section{Association Between Demographic Variables, Questionnaire Data, and PPSR Scores}

Table 1 shows the demographic data of 535 adult workers and their association with PPSR scores of the BJSQ. PPSR scores were significantly higher in young workers, women, and unmarried workers. No other demographic data were associated with PPSR score.

Table 2 shows the characteristics of adult workers (ie, their occupational contracts, job class, working condition, and overtime work hours) and their effects on PPSR. The Bonferroni test demonstrated that there were no significant differences in PPSR scores among workers with different occupational contracts, job class, working conditions, and overtime work hours.

Table 3 shows the results of correlations between the observed variables. The DTS score negatively correlated with the PSQI score $(r=-0.240, p<0.001)$ and PPSR score $(r=-0.193, p<0.001)$. A more eveningness chronotype (lower DTS score) was associated with more severe sleep disturbance and higher PPSR. Meanwhile,

Table 3 Correlation (r) Between DTS, Sleep Disturbance (PSQI), Perceived Job Stressors, PPSR of BJSQ, Social Support of BJSQ, and Satisfaction of BJSQ

\begin{tabular}{|c|c|c|c|c|c|c|}
\hline $\begin{array}{l}\text { Measures } \\
\text { mean } \pm \text { SD }\end{array}$ & $\begin{array}{l}\text { DTS } \\
\text { score } \\
18.8 \pm \\
3.6\end{array}$ & $\begin{array}{l}\text { PSQI } \\
\text { score } \\
5.8 \pm 3.5\end{array}$ & $\begin{array}{l}\text { Perceived job stressors of } \\
\text { BJSQ } \\
40.6 \pm 6.2\end{array}$ & $\begin{array}{l}\text { PPSR of } \\
\text { BJSQ } \\
52.4 \pm 14.3\end{array}$ & $\begin{array}{l}\text { Social support of } \\
\text { BJSQ } \\
\text { 19.2 } \pm 5.4\end{array}$ & $\begin{array}{l}\text { Satisfaction of } \\
\text { BJSQ } \\
5.8 \pm 1.3\end{array}$ \\
\hline DTS score & & $\begin{array}{l}r= \\
-0.240 \\
p<0.001\end{array}$ & $\begin{array}{l}r=-0.083 \\
p=0.054\end{array}$ & $\begin{array}{l}r=-0.187 \\
p<0.001\end{array}$ & $\begin{array}{l}r=-0.064 \\
p=0.140\end{array}$ & $\begin{array}{l}r=0.087 \\
p=0.045\end{array}$ \\
\hline PSQI score & & & $\begin{array}{l}r=0.242 \\
p<0.001\end{array}$ & $\begin{array}{l}r=0.498 \\
p<0.001\end{array}$ & $\begin{array}{l}r=0.318 \\
p<0.001\end{array}$ & $\begin{array}{l}r=-0.294 \\
p<0.001\end{array}$ \\
\hline $\begin{array}{l}\text { Perceived job stressors of } \\
\text { BJSQ }\end{array}$ & & & & $\begin{array}{l}r=0.440 \\
p<0.001\end{array}$ & $\begin{array}{l}r=0.334 \\
p<0.001\end{array}$ & $\begin{array}{l}r=-0.375 \\
p<0.001\end{array}$ \\
\hline PPSR of BJSQ & & & & & $\begin{array}{l}r=0.368 \\
p<0.001\end{array}$ & $\begin{array}{l}r=-0.430 \\
p<0.001\end{array}$ \\
\hline Social support of BJSQ & & & & & & $\begin{array}{l}r=-0.566 \\
p<0.001\end{array}$ \\
\hline
\end{tabular}

Notes: For satisfaction of BJSQ, high scores indicate high satisfaction. For other subitems of BJSQ, higher the total score, the higher the stress.

Abbreviations: DTS, Diurnal Type Scale; PSQI, Pittsburgh Sleep Quality Index; BJSQ, Brief Job Stress Questionnaire; PPSR, psychological and physical stress response. 
chronotype did not significantly correlate with perceived job stressor score $(p=0.054)$.

\section{Analysis of Covariance of the Structural Model}

Figure 1 is the model analyzed by covariance structure analysis with the robust maximum likelihood estimation method using chronotype, sleep disturbance, perceived job stressors, and PPSR as observable variables. In the path analysis, morningness (higher DTS score) showed significantly negative direct effects on sleep disturbance (path effect: $-0.222, p<0.001$ ) (PPSR path effect: $-0.064, p=$ 0.047 ) and perceived job stressors (path effect: $-0.083, p=$ 0.047) (Table 4). In other words, eveningness directly increased sleep disturbance and had a small exacerbation effect on perceived job stressors and PPSR when the correlations of each association were adjusted. In addition, perceived job stressors had positive direct effects on PPSR (path effect: 0.328) and sleep disturbance (path effect: 0.223). Sleep disturbance also had a positive direct effect on PPSR (path effect: 0.421).

Regarding indirect effects, morningness showed a significantly negative indirect effect on PPSR through sleep disturbance (path effect: $-0.093, p<0.001$ ) (Table 4). In addition, perceived job stressors also showed a significantly positive indirect effect on PPSR through sleep disturbance (path effect: 0.094, $p<0.001)$. On the other hand, the indirect effects of morningness on PPSR (path effect: $-0.027, p=0.053$ ) and sleep disturbance (path effect: $-0.019, p=0.064$ ) through perceived job stressors were not significant. Furthermore, the indirect effect of morningness on PPSR through both perceived job stressors and sleep disturbance pathways was not significant (path effect: $0.008, p=0.066$ ). Sleep disturbance mediated the indirect effects of the eveningness chronotype and perceived job stressors on PPSR evaluated by BJSQ. The eveningness chronotype increased the psychological and physical stress response through sleep disturbance. This model accounted for $37.3 \%$ of the variability in the psychological and physical stress response of adult workers $\left(R^{2}=0.373\right)$.

We performed path analyses on six subitems of the PPSR, namely, activity, anger, fatigue, tension/anxiety, depression, and physical stress response, and obtained the same results as those of total PPSR scores (data not shown).

Table 4 Standardized Path Coefficients Between Each Variable

\begin{tabular}{|c|c|c|c|}
\hline \multirow[t]{2}{*}{ From } & \multicolumn{3}{|l|}{ Direct Effect on } \\
\hline & Job Stressors & Sleep Disturbance (PSQI) & PPSR \\
\hline \multirow{5}{*}{$\begin{array}{l}\text { Diurnal Type Scale } \\
\text { Job stressors } \\
\text { PSQI }\end{array}$} & $-0.083 *$ & $-0.222 * * *$ & $-0.064 *$ \\
\hline & & $0.223^{* * *}$ & $0.328 * * *$ \\
\hline & & & $0.421 * * *$ \\
\hline & \multicolumn{3}{|l|}{ Indirect effect on } \\
\hline & Job stressors & $\begin{array}{l}\text { Sleep disturbance } \\
\text { (PSQI) }\end{array}$ & PPSR \\
\hline \multirow[t]{4}{*}{ Diurnal Type Scale } & via Job stressors & -0.019 & -0.027 \\
\hline & via PSQI & & $-0.093^{* * *}$ \\
\hline & via Job stressors + PSQI & & -0.008 \\
\hline & Total indirect effect & & $-0.129 * * *$ \\
\hline \multirow[t]{3}{*}{ Job stressors } & via PSQI & & $0.094 * * *$ \\
\hline & \multicolumn{3}{|l|}{ Total effect on } \\
\hline & Job stressors & $\begin{array}{l}\text { Sleep disturbance } \\
\text { (PSQI) }\end{array}$ & PPSR \\
\hline Diurnal Type Scale & $-0.238 * * *$ & $-0.240 * * *$ & $-0.193 * * *$ \\
\hline Job stressors & & - & $0.422 * * *$ \\
\hline
\end{tabular}

Notes: $*_{p}<0.05, *_{*} *_{p}<0.001$.

Abbreviations: PSQI, Pittsburgh Sleep Quality Index; PPSR, psychological and physical stress response. 


\section{Discussion}

In this study, direct and indirect effects of chronotype on sleep disturbance, perceived job stressors, and PPSR in adult workers were investigated by covariance structure analysis. The results of our study showed that the eveningness indirectly increases PPSR through its effects on sleep disturbance. In addition, perceived job stressors directly increased PPSR and indirectly increased PPSR through their effects on sleep disturbance. These results partly support our hypothesis stated in the introduction. However, contrary to our hypothesis, chronotype influenced perceived job stressors only slightly and did not show indirect effects on PPSR or sleep disturbance through perceived job stressors. Therefore, our results demonstrate that chronotype affects PPSR via sleep disturbance independently of perceived job stressors. Chronotypes that do not match the social life of workers, in addition to job stressors, may lead to impaired sleep and job stress responses. There have been no studies to date on the effects of chronotype on job stress. This is the first study to our knowledge showing the effects of chronotype on the stress response, mediated by sleep disturbance, although there are some limitations regarding the interpretation of the results, as described below.

Many studies have reported the association between chronotype and sleep. ${ }^{9,30}$ Wittmann and colleagues defined the discrepancy between social time and biological time as "social jetlag", and they showed that social jetlag negatively affects psychological well-being. ${ }^{31}$ Taillard et al (1999) reported that the eveningness leads to social jetlag, resulting in sleep debt and being prone to daytime sleepiness. ${ }^{8}$ Núñez et al (2019) conducted a comparative study on young undergraduate students and senior, ${ }^{32}$ and found that young undergraduates showed more eveningness than senior did. They also showed that students with eveningness were more likely to have sleep disturbance. A review also pointed out that evening type people are more likely to have sleep disturbance and to be more susceptible to depression. ${ }^{9}$ Thus, it is well known that the eveningness has an adverse effect on sleep disturbance. Consistent with the results of previous studies, our present study demonstrated that eveningness directly increases sleep disturbance, and hence this phenomenon is considered to be universal. The association between sleep disturbance and job stress was reported by Nishitani et al (2010) and Yang et al (2018). ${ }^{17,18}$ Nishitani et al (2010) analyzed 212 male workers using multiple regression analysis and reported that job stressors and PPSR were closely associated with sleep disturbance. ${ }^{18}$ They noted that depression and physical stress response among the 6 PPSR subitems (activity, anger, fatigue, tension/anxiety, depression, and physical stress response) were significantly associated with insomnia. ${ }^{18}$ Our results were partly consistent with their results, because, in our present study, these 6 PPSR subitems showed the same results on path analyses as total PPSR scores. Yang et al (2018) reported a meta-analysis showing that high-level job stressors increased the risk of sleep disturbance. ${ }^{17}$ In addition, we previously reported an indirect effect of job stressors on PPSR through their effects on sleep disturbance. ${ }^{19}$ Consistent with the results of earlier studies, the present study demonstrated a mediating effect of sleep disturbance on the association between job stressors and PPSR.

In this study, sleep disturbance mediated the indirect effects of chronotype on PPSR. As mentioned in the introduction, this is the first study to our knowledge on the association between chronotype and job stress. Our univariate analysis on the association between chronotype and job stress demonstrated that eveningness significantly and positively associated with PPSR, but not with perceived job stressors. On the other hand, in the path analysis, chronotype only had small direct effects on both perceived job stressors and PPSR, which were smaller than the indirect effect of chronotype on PPSR through sleep disturbance. Furthermore, the direct effect of chronotype on perceived job stressors was not linked to PPSR. Therefore, the main effect of chronotype on job stress appears to be its indirect effect on PPSR through its effect on sleep disturbance.

It has been reported that shift work and overwork for many days may influence sleep and then chronotype conversely. ${ }^{1}$ This idea may explain in reverse the association demonstrated in our present study between chronotype and job stress. We conducted another path analysis on 318 workers, excluding workers performing overtime (41 $\mathrm{h}$ or more) and shift workers (results not shown). This additional analysis showed similar results regarding the direct and indirect effects found in the present study. Therefore, shift work and overtime work may not have affected the results of the path analysis in this study. Future studies will be needed to confirm the causality between chronotype and job stress.

Shimura et al (2018) reported that in high-school students, eveningness increased daytime sleepiness through its effect on sleep disturbance. ${ }^{33}$ They further suggested 
that improving sleep hygiene and lifestyle could improve sleep disturbance. ${ }^{33,34}$ In their research, as the direct effect of chronotype on daytime sleepiness without mediation by sleep disturbance was also significant, the significant direct effect of chronotype on PPSR observed in our study may have been mediated by daytime sleepiness. Therefore, the sleep disturbance of workers may be improved by intervening with sleep hygiene and lifestyle habits, or by adequately designing working hours so as not to shorten sleep time. Such measures are expected to reduce job stress.

There are some limitations to our present study. First, as this study used self-administered questionnaires, there is the possibility that there was subjective bias when the workers answered the questions, and the subjective results may deviate from objective results. Second, as this is a crosssectional study, we cannot conclude the causal association between the factors. Third, mood may affect the results of the path analysis, because chronotype is associated with mood problems, as mentioned in the Introduction section. ${ }^{10,11}$ We conducted path analysis on the same participants with the addition of depressive symptoms. The direct and indirect effects of chronotype on PPSR through sleep disturbance were still significant in the new model (results not shown). Therefore, we believe that our model is likely to be independent of depressive symptoms. Nevertheless, because moods other than depressive symptoms may affect chronotype, a prospective study analyzing the effects of mood on chronotype should be conducted in the future. Furthermore, contrary to the results of this study, it may be possible that job stress affects sleep disturbance, and subsequently, sleep disturbance affects chronotype. Therefore, it is necessary to confirm the causal association between factors through a long-term prospective study in the future.

\section{Conclusion}

Our study clarified the association between chronotype, perceived job stressors, stress responses, and sleep disturbance by path analysis. The eveningness indirectly affected the psychological and physical stress response through sleep disturbance. Therefore, improving sleep disturbance in evening type people may lead to a reduced job stress response. In the future, evaluating chronotype as part of the industrial hygiene of workers is expected to clarify the association between chronotype, the job stress response, and sleep disturbance, and may enable us to take measures against job stress for each individual.

\section{Acknowledgments}

This work was supported in part by a Grant-in-Aid for Scientific Research (no. 16K10194, to T. Inoue) from the Japanese Ministry of Education, Culture, Sports, Science and Technology, Research and Development Grants for Comprehensive Research for Persons with Disabilities from the Japan Agency for Medical Research and Development (AMED), and a grant from the SENSHIN Medical Research Foundation to $T$, Inoue. The authors thank Dr. Nobutada Takahashi of Fuji Psychosomatic Rehabilitation Institute Hospital, Dr. Hiroshi Matsuda of Kashiwazaki Kosei Hospital, deceased Dr. Yasuhiko Takita of Maruyamasou Hospital, and Dr. Yoshihide Takaesu of Izumi Hospital for collecting data.

\section{Author Contributions}

All authors made substantial contributions to conception and design, acquisition of data, or analysis and interpretation of data; took part in drafting the article or revising it critically for important intellectual content; gave final approval of the version to be published; and agree to be accountable for all aspects of the work.

\section{Disclosure}

Akiyoshi Shimura has received fees from Meiji Seika Pharma, Yoshitomi Yakuhin, Tanabe Mitsubishi Pharma, and Eisai outside of the submitted work and is a stockholder of Children and Future Co., Ltd. Jiro Masuya has received personal compensation from Otsuka Pharmaceutical, Eli Lilly, Astellas, and Meiji Yasuda Mental Health Foundation, and grants from Pfizer. Takeshi Inoue has received personal fees from Mochida Pharmaceutical, Takeda Pharmaceutical, Eli Lilly, Janssen Pharmaceutical, MSD, Taisho Toyama Pharmaceutical, Yoshitomiyakuhin, and Daiichi Sankyo; grants from Shionogi, Astellas, Tsumura, and Eisai; and grants and personal fees from Otsuka Pharmaceutical, Dainippon Sumitomo Pharma, Mitsubishi Tanabe Pharma, Kyowa Pharmaceutical Industry, Pfizer, Novartis Pharma, and Meiji Seika Pharma; and is a member of the advisory boards of Pfizer, Novartis Pharma, and Mitsubishi Tanabe Pharma. The other authors declare that they have no actual or potential conflicts of interest.

\section{References}

1. Adan A, Archer SN, Hidalgo MP, Di Milia L, Natale V, Randler C. Circadian typology: a comprehensive review. Chronobiol Int. 2012;29:1153-1175. doi:10.3109/07420528.2012.719971 
2. Koskenvuo M, Hublin C, Partinen M, Heikkilä K, Kaprio J. Heritability of diurnal type: a nationwide study of 8753 adult twin pairs. J Sleep Res. 2007;16:156-162. doi:10.1111/j.1365-2869.20 07.00580.x

3. Roenneberg T, Kuehnle T, Pramstaller PP, et al. A marker for the end of adolescence. Curr Biol. 2004;14:1038-1039. doi:10.1016/j.cub.20 04.11 .039

4. Fischer D, Lombardi DA, Marucci-Wellman H, Roenneberg T, Tosini G. Chronotypes in the US - Influence of age and sex. PLoS One. 2017;12:e0178782. doi:10.1371/journal.pone.0178782

5. Horne JA, Ostberg O. A self-assessment questionnaire to determine morningness-eveningness in human circadian rhythms. Int J Chronobiol. 1976;4:97-110.

6. Roenneberg T, Wirz-Justice A, Merrow M. Life between clocks: daily temporal patterns of human chronotypes. J Biol Rhythms. 2003;18:80-90. doi:10.1177/0748730402239679

7. Torsvall L, Akerstedt T. A diurnal type scale. Construction, consistency and validation in shift work. Scand J Work Environ Health. 1980;6:283-290. doi:10.5271/sjweh.2608

8. Taillard J, Philip P, Bioulac B. Morningness/eveningness and the need for sleep. J Sleep Res. 1999;8:291-295. doi:10.1046/j.13652869.1999.00176.x

9. Kivelä L, Papadopoulos MR, Antypa N. Chronotype and psychiatric disorders. Curr Sleep Med Rep. 2018;4:94-103. doi:10.1007/s40675018-0113-8

10. Au J, Reece J. The relationship between chronotype and depressive symptoms: a meta-analysis. J Affect Disord. 2017;218:93-104. doi:10.1016/j.jad.2017.04.021

11. Park H, Lee HK, Lee K. Chronotype and suicide: the mediating effect of depressive symptoms. Psychiatry Res. 2018;269:316-320. doi:10.1016/j.psychres.2018.08.046

12. Van den Berg JF, Kivelä L, Antypa N. Chronotype and depressive symptoms in students: an investigation of possible mechanisms. Chronobiol Int. 2018;35:1248-1261. doi:10.1080/07420528.2018. 1470531

13. Li L, Wu C, Gan Y, Qu X, Lu Z. Insomnia and the risk of depression: a meta-analysis of prospective cohort studies. BMC Psychiatry. 2016;16:375. doi:10.1186/s12888-016-1075-3

14. Shimomitsu T, Haratani T, Nakamura K, et al. Final development of the Brief Job Stress Questionnaire mainly used for assessment of the individuals. In: Kato M, editor. The Ministry of Labor Sponsored Grant for the Prevention of Work-Related Illness, FY 1999 Report. Tokyo: Tokyo Medical University; 2000:126-164.

15. Ando E, Kawakami N, Shimazu A, Shimomitsu T, Odagiri Y Reliability and validity of the English version of the New Brief Job Stress Questionnaire. Presented at the 31st International Conference on Occupational Health. May 31 - June 5; 2015; Seoul, Korea.

16. Wada K, Sairenchi T, Haruyama Y, Taneichi H, Ishikawa Y, Muto T. Relationship between the onset of depression and stress response measured by the Brief Job Stress Questionnaire among Japanese employees: a cohort study. PLoS One. 2013;8:e56319. doi:10.1371/ journal.pone. 0056319

17. Yang B, Wang Y, Cui F, et al. Association between insomnia and job stress: a meta-analysis. Sleep Breath. 2018;22:1221-1231. doi:10.10 07/s11325-018-1682-y

18. Nishitani N, Sakakibara H. Job stress factors, stress response, and social support in association with insomnia of Japanese male workers. Ind Health. 2010;48:178-184. doi:10.2486/indhealth.48. 178
19. Shimura A, Tanaka T, Misaki S, et al. Assessment of the effect of sleep disturbance and occupational stress on the stress response. Seishin Igaku. 2018;60:783-791.

20. Roenneberg T, Kuehnle T, Juda M, et al. Epidemiology of the human circadian clock. Sleep Med Rev. 2007;11:429-438. doi:10.1016/j. smrv.2007.07.005

21. Foster RG, Roenneberg T. Human responses to the geophysical daily, annual and lunar cycles. Curr Biol. 2008;18:784-794. doi:10.1016/j. cub.2008.07.003

22. Adolescent Sleep Working Group; Committee on Adolescence; Council on School Health. School start times for adolescents. Pediatrics. 2014;134:642-649. doi:10.1542/peds.2014-1697

23. Hida A, Ohsawa Y, Kitamura S, et al. Evaluation of circadian phenotypes utilizing fibroblasts from patients with circadian rhythm sleep disorders. Transl Psychiatry. 2017;7:1106. doi:10.1038/ tp. 2017.75

24. Kalmbach DA, Schneider LD, Cheung J, et al. Genetic basis of chronotype in humans: insights from three landmark GWAS. Sleep. 2017;40. doi:10.1093/sleep/zsw048

25. Hida A, Kitamura S, Enomoto M, et al. Individual traits and environmental factors influencing sleep timing: a study of 225 Japanese couples. Chronobiol Int. 2012;29:220-226. doi:10.3109/07420528. 2011.641045

26. Toyoshima K, Inoue T, Masuya J, Ichiki M, Fujimura Y, Kusumi I. Evaluation of subjective cognitive function using the cognitive complaints in bipolar disorder rating assessment (COBRA) in Japanese adults. Neuropsychiatr Dis Treat. 2019;15:2981-2990. doi:10.2147/ NDT.S218382

27. Asaoka S, Aritake S, Komada Y, et al. Factors associated with shift work disorder in nurses working with rapid-rotation schedules in Japan: the nurses' sleep health project. Chronobiol Int. 2013; 30:628-636. doi:10.3109/07420528.2012.762010

28. Doi Y, Minowa M, Uchiyama M, et al. Psychometric assessment of subjective sleep quality using the Japanese version of the Pittsburgh Sleep Quality Index (PSQI-J) in psychiatric disordered and control subjects. Psychiatry Res. 2000;97:165-172. doi:10.1016/S01651781(00)00232-8

29. Buysse DJ, Reynolds CF, Monk TH, Berman SR, Kupfer DJ. The Pittsburgh Sleep Quality Index: a new instrument for psychiatric practice and research. Psychiatry Res. 1989;28:193-213. doi:10. 1016/0165-1781(89)90047-4

30. Merikanto I, Kronholm E, Peltonen M, Laatikainen T, Lahti T, Partonen T. Relation of chronotype to sleep complaints in the general Finnish population. Chronobiol Int. 2012;29:311-317. doi:10.3109/ 07420528.2012.655870

31. Wittmann M, Dinich J, Merrow M, Roenneberg T. Social jetlag: misalignment of biological and social time. Chronobiol Int. 2006;23:497-509. doi:10.1080/07420520500545979

32. Núñez P, Perillan C, Arguelles J, Diaz E. Comparison of sleep and chronotype between senior and undergraduate university students. Chronobiol Int. 2019;36:1626-1637. doi:10.1080/07420528.2019. 1660359

33. Shimura A, Hideo S, Takaesu Y, Nomura R, Komada Y, Inoue T. Comprehensive assessment of the impact of life habits on sleep disturbance, chronotype, and daytime sleepiness among high-school students. Sleep Med. 2018;44:12-18. doi:10.1016/j.sleep.2017.10.011

34. Shimura A, Sugiura K, Inoue M, et al. Which sleep hygiene factors are important? Comprehensive assessment of lifestyle habits and job environment on sleep among office workers. Sleep Health. 2020. 


\section{Publish your work in this journal}

Neuropsychiatric Disease and Treatment is an international, peerreviewed journal of clinical therapeutics and pharmacology focusing on concise rapid reporting of clinical or pre-clinical studies on a range of neuropsychiatric and neurological disorders. This journal is indexed on PubMed Central, the 'PsycINFO' database and CAS, and is the official journal of The International Neuropsychiatric Association (INA). The manuscript management system is completely online and includes a very quick and fair peer-review system, which is all easy to use. Visit http://www.dovepress.com/testimonials.php to read real quotes from published authors.

Submit your manuscript here: https://www.dovepress.com/neuropsychiatric-disease-and-treatment-journal 